Document downloaded from:

http://hdl.handle.net/10251/89487

This paper must be cited as:

Martínez Las Heras, R.; Pinazo, A.; Heredia Gutiérrez, AB.; Andrés Grau, AM. (2017). Evaluation studies of persimmon plant (Diospyros kaki) for physiological benefits and bioaccessibility of antioxidants by in vitro simulated gastrointestinal digestion. FOOD CHEMISTRY. 214(0):478-485. doi:10.1016/j.foodchem.2016.07.104

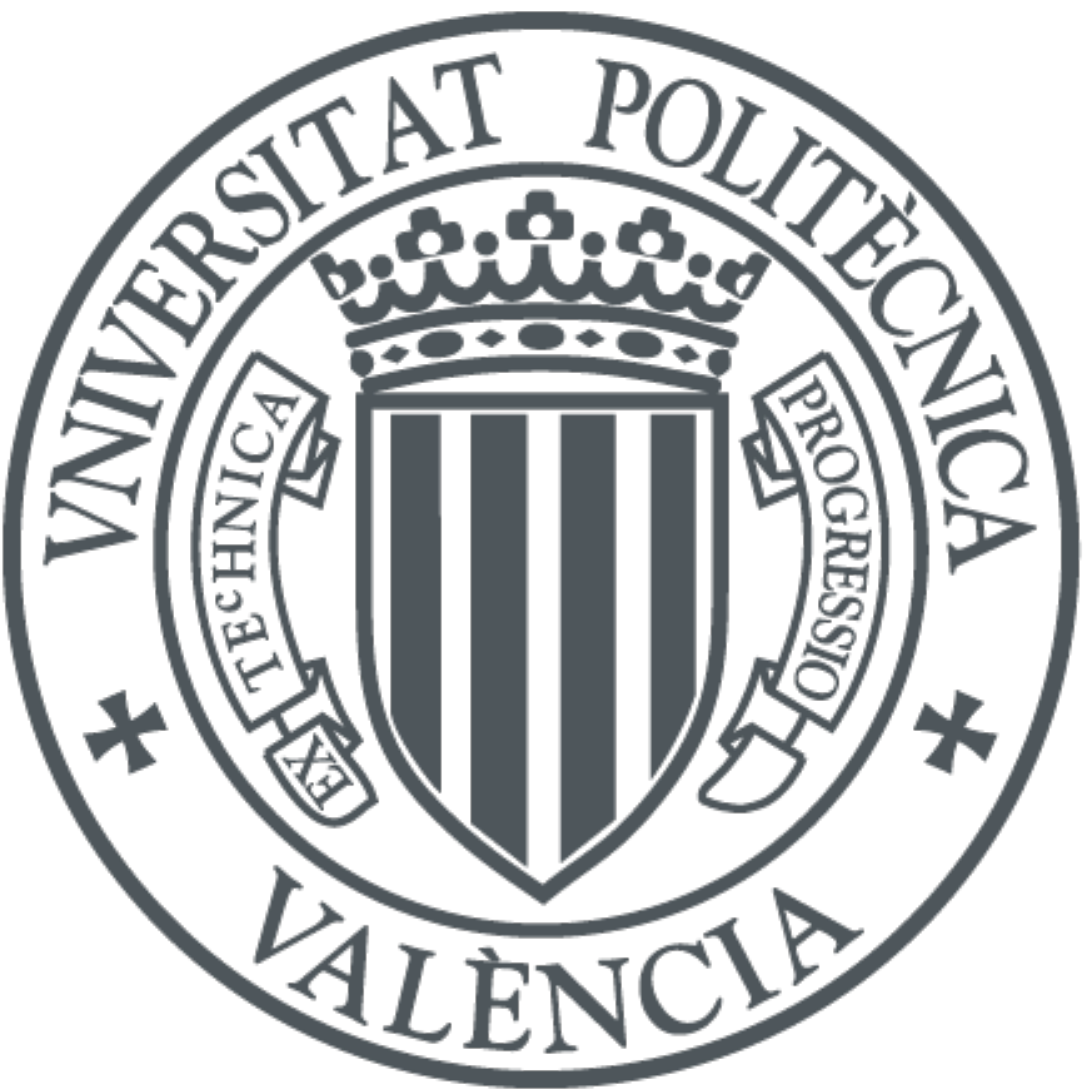

The final publication is available at

http://dx.doi.org/10.1016/j.foodchem.2016.07.104

Copyright

Additional Information 


\title{
III.5. EVALUATION STUDIES OF PERSIMMON PLANT (DIOSPYROS KAKI) FOR PHYSIOLOGICAL BENEFITS AND BIOACCESSIBILITY OF ANTIOXIDANTS BY IN VITRO SIMULATED GASTROINTESTINAL DIGESTION
}

\author{
Martínez-Las Heras, R., Pinazo, A., Heredia, A., Andrés, A.
}

Food Chemistry 214: 478-485 (2017)

\section{ABSTRACT}

This study aims to analyze the antioxidant benefits from persimmon leaf tea, fruit and fibres taking into account their changes along gastrointestinal digestion. The evolution of polyphenols, flavonoids and antioxidant capacity was studied using the recent harmonized in vitro protocol published by Minekus et al. (2014). The digestion was performed with and without digestive enzymes. Results showed aqueous leaf extract was richer in antioxidants than the fruit or the extracted fibres. Nevertheless, persimmon-leaf antioxidants were more sensitive to the digestive environment. In general, the oral conditions greatly affected the antioxidants, while gastric digestion led to slight additional losses. The intestinal step enhanced polyphenols and flavonoids solubility coming from the fruit and fibres. Additionally, the presence of digestive enzymes positively contributed to antioxidant release throughout digestion. Finally, the bioaccesibility of polyphenols, flavonoids and antioxidant activity of persimmon fruit were 1.4, 1.0 and 3.8 times higher than in aqueous leaf extract.

Keywords: persimmon; fibres; leaf-aqueous extract; antioxidant compounds; gastro-intestinal digestion; bioaccessibility.

\section{INTRODUCTION}


Since it is better to prevent chronic diseases than to treat them, reducing the risk of cardiovascular diseases or cancer has become one of the priorities of sanitary authorities, scientists and the food industry. The consumption of functional foods enriched in antioxidants as well as fruits and vegetables naturally rich in bioactive compounds would contribute to reducing the risk of suffering from diseases associated with oxidative stress. Although it is true that the presence of bioactive compounds in the diet is linked to the aforementioned benefit, their repercussion in human health mainly depends on biochemical state they are in when they reach the bloodstream and, consequently the tissues. The digestion process itself leads to a series of changes in the macro and micronutrients conditioning their final bioaccessibility and bioavailability (Parada \& Aguilera, 2007). The bioavailability of dietary compounds in general, and phytochemicals in particular, is dependent on their digestive stability, their release from the food matrix and the efficiency of their transepithelial passage. The best way to determine the benefits arising from the intake of foods, and its bioavailability, consists of subjecting the product to in vivo gastrointestinal digestion. However, in vivo trials are expensive and require long periods of observation, especially in human samples. Besides, they involve medical and ethical implications. Due to these limitations, scientific evidences positively support the alternative to employing in vitro models to accurately reproduce the biochemical conditions of different phases involved in the gastrointestinal digestion (During \& Harrison, 2005). In vitro simulated digestion presents additional advantages compared with in vivo trials such as the possibility of sampling at different times of digestion process and eluding the inter-human body variability. Therefore, the evaluation of the influence of matrix food structure on antioxidant changes along gastrointestinal digestion by means of an in vitro simulation could considered as a valid approach. In this sense, authors decided to explore the influence of structure of food matrices all coming from Persimmon crop on the changes experimented by antioxidants during 
gastrointestinal digestion. Concretely, food matrices selected for this study were the persimmon fruit, the fibre, a functional ingredient extracted from the fruit, and the aqueous extract of persimmon dried leaves. Persimmon crop is native to China where it has been cultivated for centuries before Christ. It spread to Japan (c. VII) and Korea (c. XIV) in Middle Ages, and posteriorly to other continents. Persimmon cultivars can be divided into two distinct groups: astringent (Rojo brillante, Triumph, etc.) and non-astringent varieties (Fuyu, Hana-Fuyu, Jiro, etc.). Astringency is linked to the chemical structure of the tannins in the fruit, being insolubilized in non-astringency varieties and soluble in astringent ones. Soluble tannins can interact with proteins of saliva that gives rise to a bitter taste in mouth. As ripening progresses, the tannin content decrease and the risk of bitter taste in astringent varieties as well (Hernándiz, 1999). Nevertheless, some astringent varieties such as Rojo brillante are harvested unripened because of its demanding texture. Rojo brillante is the most important commercial variety in Valencian Community (Spain). According to data from Agricultural Minister of Spain, the land dedicated to persimmon crop has significantly increased in the recent past years (only in the last year it has increased an additional 20\%) (Alòs, 2014), and subsequently the fruit production. This fact is partially due to the implementation of new technologies capable to remove astringency in unripened fruits that allow offering persimmons with firm texture and without astringency to consumers (Arnal \& Del Río, 2005). Parallely, this rapid increase of production has led to an overproduction due to both the seasonality of the persimmon culture and fruits do not meet market standards. Due to this situation, alternatives to obtain higher economical return from the culture have being explored. In this sense, the use of dried persimmon leaves in infusions or the inclusion of aqueous leaf-extract in functional food formulations could be attractive because of the high antioxidant content in this food matrix (Martínez-Las Heras, Quifer-Rada, Andrés \& Lamuela-Raventós, 2016). The extraction of functional ingredients from persimmon fruit such as fibre could 
be also interesting (Landines, Martínez-Las Heras, Heredia, \& Andrés, 2014). Currently, fibres are used in many foods such as yoghourts or bakery products in order to improve the texture and viscosity of the product, and because of their prebiotic potential (Thebaudin, Lefebvre, Harrington, \& Bourgeois, 1997; Guevara-Cruz, 2013). Fibre consumption is associated with the prevention and treatment of some diseases such as colon cancer, coronary diseases, constipation and, diabetes as well as antioxidants (Sorensen, Hsi, Chi, Shara, Wactawski-Wende, Kahn, \& Stoller, 2014). In this context, the aim of this study was to determine the changes undergone by total polyphenols, flavonoids and antioxidant capacity of persimmon aqueous leaf extract, fruit and fibre, extracted from the pulp and peel of persimmon fruit and stabilized by hot air drying or freeze-drying, during gastrointestinal digestion by means of an in vitro simulation. Besides, the bioaccessibility of these antioxidant families was determined.

\section{MATERIALS AND METHODS}

\subsection{Raw material}

The raw materials used were persimmon tree (Diospryos kaki, Rojo brillante) leaves, fruit and fibre extracted from peel or pulp of the fruit.

Persimmon leaves were collected from an orchard in Alginet (Valencia, Spain). They were washed and blanched for $1 \mathrm{~min}$ at $100{ }^{\circ} \mathrm{C}$ and then dried by convection air current at $100{ }^{\circ} \mathrm{C}$ in an oven (30 $\mathrm{min}$ ). Once they were dehydrated, they were grounded in a grinder (Severn) till they had a particle size of less than 1 $\mathrm{mm}$. The resulting powder was finally used to prepare infusions. For this purpose, $1.5 \mathrm{~g}$ of leaf powder was mixed with $110 \mathrm{~mL}$ of boiling distilled water and were filtered with a Whatman paper (particle retention: 20-25 $\mu \mathrm{m}$ ) after 5 min (Martínez-Las Heras, Heredia, Castelló, \& Andrés, 2014). 
The persimmon fruits were also collected in Alginet (Valencia, Spain). They were kept at environmental conditions for approximately $24 \mathrm{~h}$. They were then subjected to a deastringency treatment in closed chambers with $95 \%$ of $\mathrm{CO} 2$ at $20^{\circ} \mathrm{C}$ and $90 \%$ of relative humidity for $24 \mathrm{~h}$. Subsequently, the persimmon fruits were washed, peeled and the pulp cut into small cubes for digestion. Additionally, fibre was extracted from persimmon peel or pulp according to Escalada, González, Sette, Portillo, Rojas, \& Gerschenson (2012). For this purpose, each fraction (peel and pulp) was separately homogenized with a high-performance dispersing instrument (T25 digital Ultraturrax IKA). Each fraction was mixed with boiling ethanol $(96 \% \mathrm{v} / \mathrm{v})$ in a ratio $1: 2(\mathrm{w} / \mathrm{v})$ and the mixture was stirred at 600 rpm for 15 min. Finally, the ethanol was discarded by a sieve from the mixture and the semi-solid residue subjected to the Van Soest official method (Van Soest, Robertson, \& Lewis, 1991 ) in order to confirm that it was fibre. Once the presence of fibre confirmed, it was dehydrated in a hot-air oven at $40^{\circ} \mathrm{C}$ till it reached a constant mass (approximately $7 \mathrm{~h}$ ), or frozen at $40^{\circ} \mathrm{C}$ for $24 \mathrm{~h}$ and then freeze-dried (vacuum pressure of 10-1 mbar for $24 \mathrm{~h}$ ). Therefore, four different fractions of fibre were obtained: PULP-A or PULP-F for hot-air dried or lyophilized pulp fibres; and PEEL-A or PEEL-F for hot air dried or freezedried/lyophilized peel fibres. The final moisture content of each fraction was: $6 \pm 1,7.8 \pm 0.3,6.9 \pm 0.5$ and $8 \pm 1 \%$ for PULP-A, PULP-F, PEEL-A and PEEL-F, respectively.

2.2. In vitro simulated gastrointestinal digestion (GI) of persimmon food matrices

In vitro gastrointestinal digestion (oral, gastric and intestinal phases) was simulated following the harmonized INFOGEST protocol published by Minekus et al., (2014). According to this method, simulated salivary fluid (SSF), simulated gastric fluid (SGF) and simulated intestinal fluid (SIF) were prepared from stock solutions fresh daily and kept at $37^{\circ} \mathrm{C}$ before their use. Stock solutions and simulated fluids were prepared with $\mathrm{KCl}$, 
$\mathrm{KH} 2 \mathrm{PO} 4, \mathrm{NaHCO} 3, \mathrm{NaCl}, \mathrm{MgCl} 2(\mathrm{H} 2 \mathrm{O}) 6$ and $(\mathrm{NH} 4) 2 \mathrm{CO} 3$ at the same molarity indicated in Minekus et al. (2014). Additionally, salivary $\alpha$-amylase from human saliva was added to the SSF in a final concentration of $75 \mathrm{U} / \mathrm{mL}$; pepsine from porcine gastric mucosa to the SGF in a final concentration of $2000 \mathrm{U} / \mathrm{mL}$; and pancreatin from porcine pancreas and bile salts (bovine bile extract) to the SIF in a final concentration of $100 \mathrm{U} / \mathrm{mL}$ and 10 $\mathrm{mM}$, respectively. All reagents and enzymes were obtained from Sigma-Aldrich Chemical Company (St Louis, MO, USA). Once simulated fluids prepared, in vitro digestion was carried out. For oral phase simulation, the different food matrixes (persimmon leaf aqueous extract, fruit and fibres) were mixed in a ratio food: SSF of $1: 1(\mathrm{w} / \mathrm{v})$, and properly homogenized. The mixture was then placed in $50 \mathrm{~mL}$ falcon tubes and incubated without agitation for $2 \min$ at $37^{\circ} \mathrm{C}$. Then, simulated gastric fluid (SGF) ( $\mathrm{pH} 3)$ was added in a ratio of $1: 1(\mathrm{v} / \mathrm{v})$ to each tube containing the oral mixture and the $\mathrm{pH}$ adjusted to 3 with $\mathrm{HCl}$ $(1 \mathrm{~N})$. The falcon tubes were placed in a head- over-heels stirrer (Intell-Mixer RM-2, Elmi Ltd, Riga, LV-1006, Latvia) at $55 \mathrm{rpm}$ for $2 \mathrm{~h}$ at $37^{\circ} \mathrm{C}$ in an incubator chamber (JP Selecta SA, Barcelona). Finally, simulated intestinal fluid (SIF) (pH 7), was added in a ratio of $1: 1(\mathrm{v} / \mathrm{v})$ to each tube containing the gastric mixture, $\mathrm{pH}$ adjusted to 7 with $\mathrm{NaOH}(1 \mathrm{~N})$ and the tubes placed in the head-over-heels stirrer at $55 \mathrm{rpm}$ and in the incubator chamber to conduct the intestinal phase simulation for $2 \mathrm{~h}$ at 37 $\stackrel{\circ}{\circ}$.

For analytical purposes, aliquots were taken at the end of each phase: oral (2 $\mathrm{min})$, gastric (120 $\mathrm{min}$ ) and intestinal one (120 $\mathrm{min}$ ) as well as the following intermediate residence times: 10, 30 , and $120 \mathrm{~min}$ for gastric and 30,60, 90 and $120 \mathrm{~min}$ of intestinal digestions. Samples were placed in an ice bath for ten minutes and $\mathrm{pH}$ was adjusted to 9 to ensure enzyme inactivation.

The role of the $\mathrm{pH}$ of digestion on the antioxidants compounds changes along digestion was parallely evaluated by means of 
carrying out the entire simulation without digestive enzymes and bile salts. Simulation in the absence of enzymes served as control.

All simulations were performed twice and three aliquots were extracted at each of the specified sampling times in each one of the simulations.

2.3. Determination of the antioxidant activity, total polyphenols and flavonoids

The antioxidant capacity (TAC) of samples was analyzed on the basis of the scavenging activity of the stable 2,2-diphenyl-1picrylhydrazyl free radical (Brand-Williams, Cuvelier \& Berset, 1995; Shahidi, Liyana-Pathirana \& Wall, 2006). Three grams (3 g) of sample was diluted with $5 \mathrm{~mL}$ of methanol and stirred for 5 min. Then the test tubes with the sample-methanol mixture were centrifuged at 10,000 rpm for $10 \mathrm{~min}$ (Medifriger BL-S, PSelecta). About $0.1 \mathrm{~mL}$ of supernatant was added to $3.9 \mathrm{~mL}$ of a methanolic DPPH solution (80:20, methanol: water) of 0.025 $\mathrm{mg} / \mathrm{mL}$. The solution was shaken and after $30 \mathrm{~min}$, the absorbance of the sample was read at $515 \mathrm{~nm}$ in a spectrophotometer (JASCO V-630) and using methanol as blank. Quantification was performed considering a standard curve of Trolox (6-Hydroxy-2,5,7,8-tetramethylchroman-2carboxylic acid) and the results were expressed as $\mathrm{mg}$ of Trolox equivalent per $g$ of dry matter.

Total phenolic content (TPC) of different samples was spectrophotometrically determined by the modified FolinCiocalteu method (Sakanaka, Tachibana \& Okada, 2005). This method is based on an extraction with methanol ( $3 \mathrm{~g}$ of sample/ $5 \mathrm{~mL}$ of methanol) in stirring conditions (200 rpm) for $1 \mathrm{~h}$ (COMECTA WY-100 horizontal stirrer). Thereafter, the mixture was centrifuged for $10 \mathrm{~min}$ at $10.000 \mathrm{rpm}$ (Medifriger BL-S, PSelecta). Then, $0.125 \mathrm{~mL}$ of supernatant were transferred to a cuvette and $0.5 \mathrm{~mL}$ of distilled water and $0.125 \mathrm{~mL}$ of FolinCiocalteu reactive added and left to rest for 6 minutes. After that 
time, $1 \mathrm{~mL}$ of distilled water and $1.25 \mathrm{~mL}$ of a solution of sodium carbonate at $7 \%$ were added. The prepared simple was left to rest for 90 min before measuring absorbance at $760 \mathrm{~nm}$ using a spectrophotometer (JASCO V-630). The absorbance was compared to a standard curve of gallic acid (GA) and the content of total polyphenols was expressed as $\mathrm{mg}$ of $\mathrm{GA}$ equivalent per $\mathrm{g}$ of dry matter.

Total flavonoid content (TFC) was measured according to the colorimetric method described by Zhishen, Mengcheng \& Jianming, 1999). Briefly, three grams (3 g) of sample were mixture with $3 \mathrm{~mL}$ of water and the mixture centrifuged for 10 min at 10,000 rpm (Medifriger BL-S, P-Selecta). Next, $0.25 \mathrm{~mL}$ of the supernatant were mixed with $1 \mathrm{~mL}$ of distilled water and $0.075 \mathrm{~mL}$ of a solution of sodium nitrite at $5 \%$. After $6 \mathrm{~min}$ of rest, $0.15 \mathrm{~mL}$ of a solution of aluminum chloride were added and 5 min later, $0.5 \mathrm{~mL}$ of sodium hydroxide $(1 \mathrm{M})$ and $2 \mathrm{~mL}$ of distilled water were also added and absorbance read at $510 \mathrm{~nm}$ using a spectrophotometer (JASCO V-630). The total content of flavonoids was expressed as $\mathrm{mg}$ catechin equivalent per $\mathrm{g}$ of dry matter.

2.4. Assessment of bioaccessibility and recovery index of antioxidant compounds

To evaluate the effect of the food matrix on the changes undergone by the polyphenols, flavonoids and total antioxidant activity along gastrointestinal in vitro digestion, the recovery and bioaccesibility indexes ( $\mathrm{Rl}$ and $\mathrm{BI}$ ) were calculated according to equations I and II (Ortega, Macià, Romero, Reguant \& Motilva, 2011), respectively:

$R I(\%)=100 \cdot A / C$

(Equation I)

$\mathrm{BI}(\%)=100 \cdot \mathrm{B} / \mathrm{C}$

(Equation II)

where $\mathrm{A}$ is either polyphenols content (mg gallic acid eq./ $\mathrm{g}$ dry matter) or flavonoid content (mg catechin eq./ g dry matter) or antioxidant capacity (mg trolox eq./ g dry matter) quantified in 
each tested food at each digestion time, B is either polyphenols or flavonoid contents or antioxidant capacity quantified in the supernatant as previously described after the complete digestion process (Granado-Lorencio, Olmedilla-Alonso, Herrero-Barbudo, Blanco-Navarro, Pérez-Sacristán \& Blázquez-García, 2008), and C is either polyphenols or flavonoid contents or antioxidant capacity quantified in the tested food before digestion and expressed in the same units.

The recovery index is related to the percentage of polyphenols, flavonoids and antioxidant capacity present in the digest at each digestion time; whereas the bioaccessibility index is defined as the percentage of polyphenols, flavonoids and antioxidant capacity that is solubilized in the chime soluble fraction after the intestinal step. Thus, this index defines the proportion of the compounds that could become available for absorption into the systematic circulation (Ortega et al., 2011).

\subsection{Statistical analysis}

Statgraphics plus (version 5.1) software was used to perform the two-way analysis of variance (multi-factor ANOVA) in order to assess the effect of the type of food matrix and presence of digestive enzymes on the recovery index of polyphenols, flavonoids and antioxidant capacity along gastrointestinal digestion and their final bioaccesibility. In cases when ANOVA showed significant differences, post hoc tests (Tukey HSD test) were applied.

\section{RESULTS AND DISCUSSION}

3.1. Antioxidant properties of food matrices previous to digestion

Table 1 shows antioxidant capacity (mg trolox eq./ $\mathrm{g}$ dry matter), polyphenol (mg gallic acid eq./ g dry matter) and flavonoid (mg chatechin eq./ $g$ dry matter) contents of the different persimmon test foods (leaves, fruit and fibres) prior to digestion. As was expected, the persimmon leaves aqueous 
extract presented the highest polyphenol content and antioxidant capacity. In comparison to other infusions, persimmon leaves could be considered more antioxidant than red tea but less than green and black teas (Anesini, Ferraro \& Filip, 2008). Fibres, and especially those extracted from the peel and stabilized by freeze-drying (PEEL-L and PULP-L), contained twice the amount of antioxidants as persimmon fruit. In a previous study carried out by the same authors (Landines, 2014), in which antioxidant, emulsifiers and rehydration properties of different commercial and persimmon fibres were analyzed, it was found that freeze-dried peel persimmon fibre was also richer in antioxidants than commercial orange, peach or lemon fibres. Therefore, persimmon fibre could be used as a functional ingredient in high-fibre food formulations. In order to have a more realistic idea of the antioxidant benefits derived from one serving of each of these persimmon test foods, it was estimated the antioxidant contribution of each serving to health. In this sense, a aqueous extract of persimmon leaves (consisting of $1.5 \mathrm{~g}$ of dried leaves in $110 \mathrm{~mL}$ of water) would provide $183 \mathrm{mg}$ trolox eq., $129 \mathrm{mg}$ gallic acid eq. and $34.3 \mathrm{mg}$ catechin eq., a piece of persimmon fruit $(200 \mathrm{~g}) 129.6 \mathrm{mg}$ trolox eq., $74.4 \mathrm{mg}$ gallic acid eq. and catechin $11.2 \mathrm{mg}$ eq.; and finally, the ingestion of $100 \mathrm{~g}$ of $5 \%$ fibre-rich product, considering that all antioxidants come from persimmon fibre would contribute to health with $31 \mathrm{mg}$ Trolox eq., $20.5 \mathrm{mg}$ gallic acid eq. and $29 \mathrm{mg}$ catechin eq. (values calculated with data of Peel-L fibre). 
Table 1. Antioxidant capacity (mg trolox eq./g dry matter), polyphenol (mg gallic acid eq. /g dry matter) and flavonoid ( $\mathrm{mg}$ catechin eq./ $\mathrm{g}$ dry matter) contents of persimmon matrices before digestion: persimmon leaves, fruit and fibres extracted from pulp and peel and stabilized by hot-air drying $(A)$ or lyophilization (L) to generate PEEL-L, PULP-L, PEEL-A and PULP-A samples. Mean and standard deviation $(n=3)$.

\begin{tabular}{lccc}
\cline { 2 - 4 } & $\begin{array}{c}\text { AA (mg Trolox/g } \\
\text { dry matter) }\end{array}$ & $\begin{array}{c}\text { Phenols (mg GA/g dry } \\
\text { matter) }\end{array}$ & $\begin{array}{c}\text { Flavonoids (mg catechin/ g dry } \\
\text { matter) }\end{array}$ \\
\hline Persimmon leaf & $122(3)^{\mathrm{a}}$ & $86(2)^{\mathrm{a}}$ & $22.9(0.7)^{\mathrm{a}}$ \\
Persimmon fruit & $3.24(0.12)^{\mathrm{c}}$ & $1.86(0.03)^{\mathrm{c}}$ & $0.70(0.05)^{\mathrm{e}}$ \\
PEEL-L Fibre & $6.2(0.2)^{\mathrm{b}}$ & $4.10(0.14)^{\mathrm{b}}$ & $5.8(0.5)^{\mathrm{b}}$ \\
PULP-L Fibre & $3.78(0.2)^{\mathrm{bc}}$ & $2.17(0.05)^{\mathrm{c}}$ & $2.95(0.14)^{\mathrm{d}}$ \\
PEEL-A Fibre & $3.11(0.06)^{\mathrm{c}}$ & $2.02(0.12)^{\mathrm{c}}$ & $2.7(0.3)^{\mathrm{d}}$ \\
PULP-A Fibre & $3.78(0.08)^{\mathrm{bc}}$ & $2.94(0.18)^{\mathrm{bc}}$ & $4.6(0.3)^{\mathrm{c}}$ \\
\hline \multicolumn{2}{c}{ Different letters in the same column denote significant differences (Turkey's test, $\mathrm{p}<0.05)$ among persimmon matrices in terms of antioxidant properties }
\end{tabular}


3.2. Changes experimented by total phenolic content and flavonoids during simulated gastrointestinal in-vitro digestion

Figure 1 shows the recovery index (\%) of total polyphenols during the simulated in vitro digestion for persimmon leaf aqueous extract, persimmon fruit and persimmon fibres in the presence and absence of digestive enzymes and bile salts; while the recovery index (\%) of flavonoids for the same food matrices is depicted in figure 2. As can be observed, the simulated gastrointestinal in vitro digestion affected the polyphenol and flavonoid compounds similarly. More specifically, the oral phase, and mainly the salivary $\mathrm{pH}$, was the step affecting the most both polyphenol and flavonoid contents regardless of the digested persimmon matrix. During the gastric digestion, slight additional losses of both families of compounds occurred without the influence of the residence time in the stomach. The modificaction of polyphenols and flavonoids along the digestive process has been widely studied in other vegetables and fruits. Losses of polyphenols of $70-75 \%$ were reported in some products such as pomegranade juice (PérezVicente, Gil-Izquierdo \& García-Viguera, 2002), apple (McDougall, Fyffe, Dobson \& Stewart, 2007), cherries (Fazzari, Fukumoto, Mazza, Livrea, Tesoriere \& Marco, 2008) or red cabbage (Bouayed, Deußer, Hoffmann \& Bohn, 2012). By contrast, the biochemical conditions of the intestinal phase led to an increase in polyphenol content of persimmon fruit and fibres, and especially those extracted from the lyophilized peel (PEEL-L). This fact was also observed in the digestion of broccoli, wine, juices and cashews as a consequence of the biochemical changes undergone by these compounds in the small intestine (Wootton-Beard, Moran \& Ryan, 2011; Chandrasekara \& Shahidi, 2012). It could be with an improved of the solubility of certain phenolic compounds, before being linked or present in a reduced form (Gião et al., 2012). Additionally, the interactions of phenolic compounds with sugars or other dietary compounds released during digestion could play a protective role in their changes during the digestion 
process, affecting their solubility and potential bioavailability (Ortega et al., 2011).

The same pattern was observed in flavonoids (figure 2) with a significant increase in these compounds during the intestinal digestion of persimmon leaf infusion and fruit. The increase of total phenolics and flavonoids in the intestinal phase could be explained by the additional time of digestion (plus $2 \mathrm{~h}$ ) as well as the effect of the intestinal enzymes and bile salts, which migh be facilated the release of phenolics bound to the matrix. Record \& Lane (2001) and Green, Murphy, Schulz, Watkins \& Ferruzzi (2007) reported losses of around $80 \%$ of different catechins in different types of tea at the end of digestion, which is therefore higher than those recorded in the infusion of persimmon leaf. Likewise, Cilla, González-Sarrías, TomásBarberán, Espín \& Barberá, (2009) obtained losses of between 64.5 and $70.1 \%$ in the content of flanan-3-oles in grape, orange and peach juices. In the study published by Bouayed, Hoffman \& Bohn, (2011), losses of flavonoids were $56 \%$ at the end of digestion. These authors partially attributed the losses to the instability of some anthocyanins under alkaline conditions of the intestine. However, in a study also carried out on apples, catechins were degraded in an acidic stomach medium and posteriorly, their concentration increased in the presence of duodenal secretions because of a possible isomerization (Kahle et al., 2011). Finally, in other study published on the bioaccesibility of bioactives compounds of cacao, catechin and epicatechin contents augmented throughout digestion. This fact could be attributed to the protector role of certain macronutrients such as lipids and the formation of micellar structures which exert protection against the degradation of these compounds and consequently increase their final bioaccesibility (Ortega, Reguant, Romero, Macià \& Motilva, 2009).

As mentioned before, the in vitro digestion was also carried out in absence of digestive enzymes and bile salts as a control. The 
results show that the presence of enzymes at any step of digestion contributed positively to the preservation and/ or release of total polyphenols and flavonoids. According to these results, it could be affirmed that the final bioaccessibility of compounds, and indeed bioavailability, will be highly dependent on the correct secretion of enzymes by the human body during digestion and specifically during the duodenal step. Pancreatin (lipase, protease and amylase enzymes) hydrolises macronutrients of the matrix given as a result a degradation of the food matrix. This phenomenon could assist the antioxidants release. Therefore, it could be concluded that polyphenol and flavonoid stability would be compromised in persons suffering of enzymes secretion insufficiencies, such as exocrine pancreatic insufficiency. Exocrine pancreatic insufficiency is a condition characterized by deficiency of the exocrine pancreatic enzymes, resulting in the inability to digest food properly, or maldigestion. 

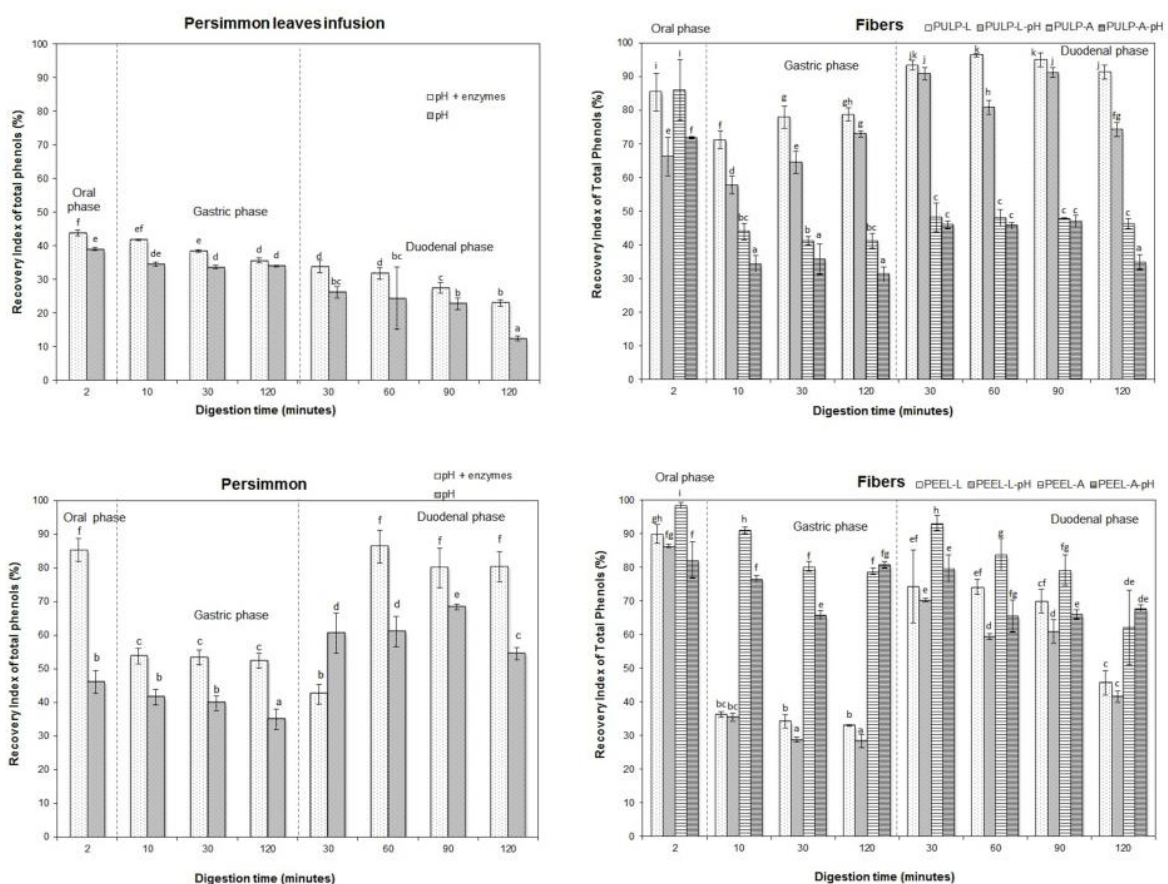

Fig. 1 - Recovery index (\%) of total polyphenols along the in-vitro simulated gastrointestinal digestion of persimmon leaves infusion, persimmon fruit and fibres extracted from pulp and peel and stabilized by hot air drying (A) or lyophilization (L) to generate PEEL-L, PULP-L, PEEL-A and PULP-A matrices. Figure shows the results obtained in presence and absence of digestive enzyme and bile salts ( $n=3)$. 

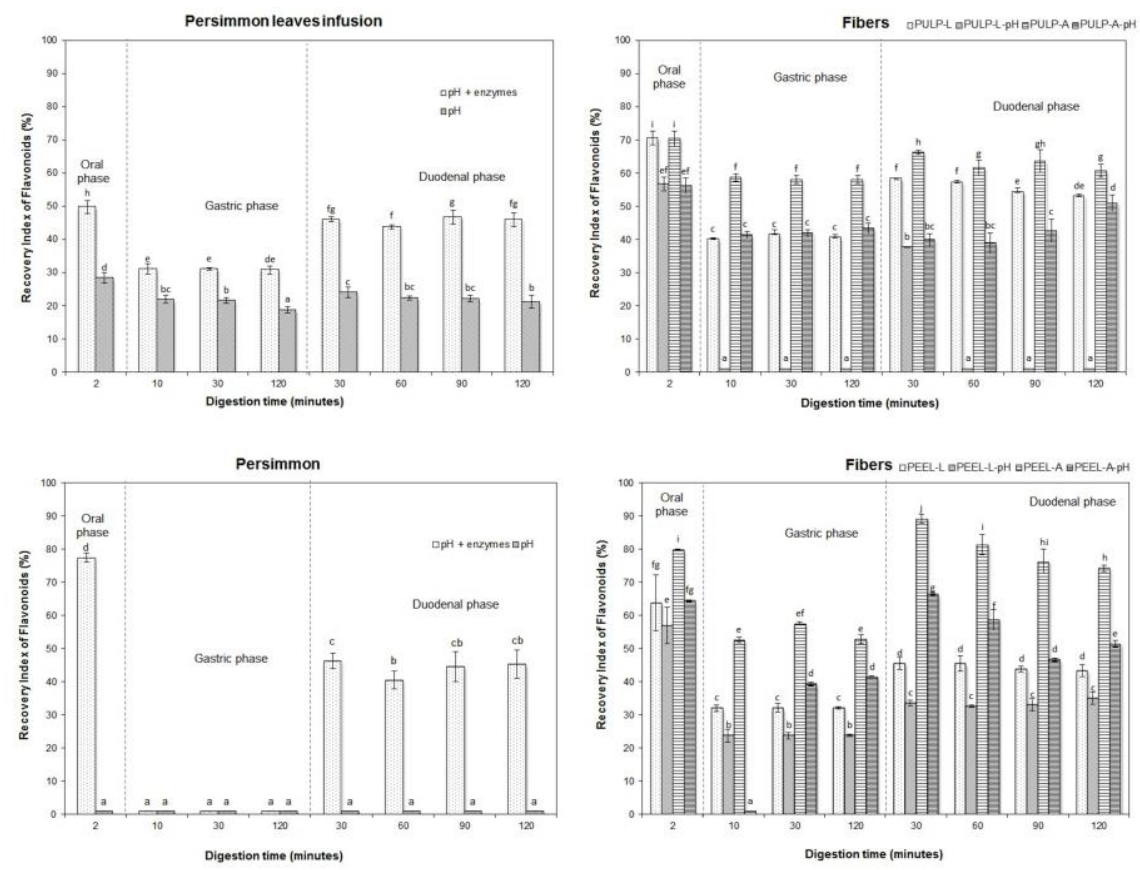

Fig. 2 - Recovery index (\%) of flavonoids along the in-vitro gastrointestinal digestion of persimmon leaves infusion, persimmon fruit and fibres extracted from pulp and peel and stabilized by hot air drying (A) or lyophilization (L) to generate PEEL-L, PULP-L, PEEL-A and PULP-A matrices. Legends called as "food matrix-pH" correspond to data obtained without digestive enzymes. Figure shows the results obtained in presence and absence of digestive enzyme and bile salts $(n=3)$. 
3.3. Changes experimented by total antioxidant activity during simulated gastrointestinal in-vitro digestion

Figure 3 shows evolution of antioxidant capacity along the gastrointestinal in vitro digestion in the presence and absence of digestive enzyme and bile salts. Changes in antioxidant capacity during digestion resulted in total losses at the end of digestion of $74,68,63,76,60$ and $66 \%$ for the persimmon leaf infusion, persimmon fruit and each of the fibres: PEEL-A, PEELL, PULP-A, PULP-L, respectively.

The residual values of antioxidant activity at the end of digestion are similar to those obtained by other authors for example, the digestion of strawberries (Cerezo, Cuevas, Winterhalter, Garcia-Parrilla \& Troncoso, 2010). However, Tavares et al., (2012) reported losses exceeding $84 \%$ of antioxidant activity in blueberries, which was higher than those obtained in this study. In contrast, some authors reported moderated losses in green and black teas (about 25\%) (Record \& Lane., 2001) or even an increase of the antioxidant capacity in fruit juices, bread or millet (Cilla, Perales, Lagarda, Barberá, Clemente \& Farré, 2011; Wootton-Beard et al., 2011, Chandrasekara \& Shahidi, 2012). 

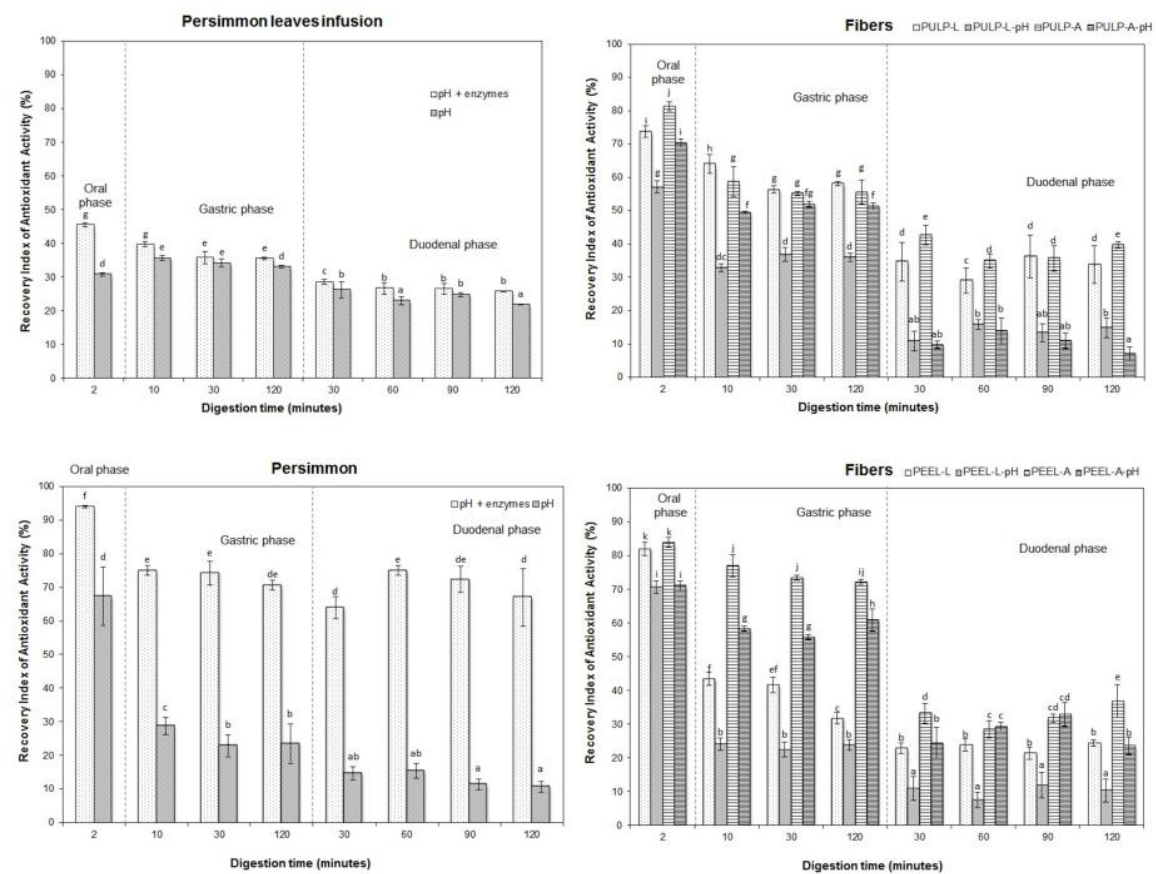

Recovery index (\%) of total antioxidant capacity along the in-vitro gastrointestinal digestion of persimmon leaves infusion, persimmon fruit and fibres extracted from pulp and peel and stabilized by hot air drying (A) or lyophilization (L) to generate PEEL-L, PULP-L, PEEL-A and PULP-A matrices. Legends called as "food matrix-pH" correspond to data obtained without digestive enzymes. Figure shows the results obtained in presence and absence of digestive enzyme and bile salts $(n=3)$. 
3.4. Bioaccesibility of polyphenols, flavonoids and total antioxidant activity of tested persimmon products

The bioaccesibility index (\%) of total polyphenols, flavonoids and total antioxidant capacity present in persimmon leaf infusion, fruit and fibres is shown in table 2. As can be observed, the bioaccesibility of any of the antioxidants studied in the persimmon fibres was higher than in the fruit and much higher than in the persimmon leaf infusion. Moreover, the bioaccesibility of the total antioxidant capacity was generally lower than those of polyphenols and flavonoids and never exceded $40 \%$. Among fibres, fibre from pulp and lyophilized is the most recommended one considering its higher values of polyphenol and flavonoid bioaccesibilities (90 and $70 \%$, respectively).

However, taking into account the total content of polyphenols, flavonoids and antioxidants capacity of a serving of persimmon leaf infusion ( $1.5 \mathrm{~g}$ in $110 \mathrm{~mL}$ of water), $200 \mathrm{~g}$ of fruit and $100 \mathrm{~g}$ of a food enriched with $5 \%$ fibre previously mentioned in this section and their bioavailability (table 2), the intake of one serving of persimmon leaf infusion would provide the same bioaccesible antioxidant capacity, half the polyphenols and three times more flavonoids than one serving of a fruit. These values are far lower for the intake of $100 \mathrm{~g}$ of a persimmon fibre-rich food despite the fact that the bioaccesibility (\%) of the compounds of this matrix (table 2) was the highest.

The analysis of variance multifactor (ANOVA multifactor) applied on changes in total antioxidant activity, polyphenols and flavonoids considering the digestion step and the presence or absence of digestive enzymes as factors, evidenced that the presence of digestive enzymes was the factor which most influenced (higher F-ratio) the evolution of the antioxidant properties along the simulated digestion of persimmon leaf infusion. In the case of the fruit, both factors showed a similar significant influence (similar values of F-ratio for both factors) on changes undergone by antioxidants during digestion; whereas 
the statistical significance of either of the factors on antioxidant changes of fibres was different for each one of the four studied fibres. Finally, in order to evaluate the influence of the raw material (pulp or peel) and the drying method (hot-air or freeze drying) on the changes of fibre-antioxidants, an additional multifactor ANOVA was performed. The analysis revealed that the drying method was the factor that influenced the most the evolution of antioxidants during digestion, and especially of the total antioxidant capacity. 
Table 2. Bioaccesibility index (\%) of polyphenols, flavonoids and total antioxidant capacity of persimmon leaf infusion, fruit and fibres extracted from pulp and peel and stabilized by hot air drying (A) or liophilization (L) to generate PEEL-L, PULP-L, PEEL-A and PULP-A samples. Means and standard deviation of bioaccesibility index $(\%)(n=3)$ at the end of the gastrointestinal digestion carried out with or without digestive enzymes and bile salts.

Bioaccesibility Index (\%)

\begin{tabular}{|c|c|c|c|c|c|c|}
\hline Test food & $\begin{array}{c}\text { Persimmon } \\
\text { leaves }\end{array}$ & $\begin{array}{c}\text { Persimmon } \\
\text { Fruit }\end{array}$ & $\begin{array}{c}\text { PEEL-A } \\
\text { Fibre } \\
\end{array}$ & $\begin{array}{c}\text { PEEL-L } \\
\text { Fibre }\end{array}$ & $\begin{array}{c}\text { PULP-A } \\
\text { Fibre } \\
\end{array}$ & $\begin{array}{c}\text { PULP-L } \\
\text { Fibre }\end{array}$ \\
\hline & \multicolumn{6}{|c|}{ Presence of digestive enzymes and bile salts } \\
\hline Poliphenols & $20.0(0.6)^{\mathrm{e}}$ & $76(3)^{b}$ & $59(3)^{\mathrm{c}}$ & $51.43(0.13)^{\mathrm{d}}$ & $46(2)^{d}$ & $91(6)^{\mathrm{a}}$ \\
\hline Flavonoids & $47.6(0.8)^{\mathrm{d}}$ & $48(3)^{\mathrm{d}}$ & $60(3)^{b}$ & $43.0(0.4)^{\mathrm{d}}$ & $53.3(0.8)^{\mathrm{c}}$ & $69.4(0.5)^{\mathrm{a}}$ \\
\hline \multirow[t]{2}{*}{ Antioxidant capacity } & $24.6(1.0)^{\mathrm{c}}$ & $33(2)^{b}$ & $32(1)^{b}$ & $25(2)^{\mathrm{c}}$ & $36(2)^{\mathrm{a}}$ & $38(2)^{\mathrm{a}}$ \\
\hline & \multicolumn{6}{|c|}{ Abscence of digestive enzymes and bile salts } \\
\hline Poliphenols & $12.1(0.4)^{\mathrm{f}}$ & $55(2)^{\mathrm{c}}$ & $67.5(0.9)^{b}$ & $42.44(0.13)^{\mathrm{d}}$ & $33(2)^{\mathrm{e}}$ & $74(6)^{\mathrm{a}}$ \\
\hline Flavonoids & $21(2)^{c}$ & ND & $35.9(0.6)^{b}$ & $39(2)^{\mathrm{a}}$ & $21.7(0.9)^{\mathrm{c}}$ & ND \\
\hline Antioxidant capacity & $21.4(0.6)^{b}$ & $11(2)^{d}$ & $28(2)^{\mathrm{a}}$ & $11.7(1.0)^{\mathrm{d}}$ & $8(4)^{d}$ & $16(3)^{\mathrm{c}}$ \\
\hline
\end{tabular}




\section{CONCLUSIONS}

It can be concluded that the polyphenols, flavonoid and total antioxidant capacity of persimmon leaf aqueous extract were more sensitive to the biochemical conditions of the gastrointestinal environment than those coming from persimmon fruit or fibres, despite being the richest source of the antioxidant compounds. More specifically, mouth digestion was the step in which all antioxidant content decreased the most, especially during the digestion of persimmon leaf infusion and persimmon fruit, while gastric digestion led to slight additional losses. The duodenal environment had a positive effect on the antioxidants evaluated. The duodenal $\mathrm{pH}$ and the presence of pancreatin and bile salts increased the solubility and release of polyphenols as well as improved the final bioaccesibility of flavonoids in all studied matrices. Additionally, results revealed a positive effect of the digestive enzymes on the bioactive compounds, thus reducing their loss along digestion and increasing their release of the food matrix.

\section{ACKNOWLEDGMENTS}

The authors thank the Universitat Politècnica de València for the PhD scholarship given to Ruth Martínez-Las Heras.

\section{REFERENCES}

Alòs, C. (2014). La superficie cultivada de caqui crece un $20 \%$ en 2013 y se quintuplica en una década, Dirección URL: http://www.levante-

emv.com/comarcas/2014/01/10/superficie-cultivadacaqui-crece-20/1067085.htmL. Assessed: 14.02.16

Anesini, C., Ferraro, G. E., \& Filip, R. (2008). Total polyphenol content and antioxidant capacity of commercially available tea (Camellia sinensis) in Argentina. Journal of Agricultural and Food Chemistry, 56(19), 9225-9229. 
Arnal Navarro, L. \& Del Río Gimeno, M.A. (2005). La astringencia del caqui. Fruticultura Profesional, 149, 1418.

Bouayed, J., Hoffman, L. \& Bohn, T. (2011). Total phenolics, flavonoids, anthocyanins and antioxidant activity following simulated gastro-intestinal digestion and dialysis of apple varieties: Bioaccessibility and potencial uptake. Food Chemistry, 128:14-21.

Bouayed, J., Deußer, H., Hoffmann, L. \& Bohn, T. (2012). Bioaccessible and dialysable polyphenols in selected apple varieties following in vitro digestion vs. their native patterns. Food Chemistry, 131, 1466-1472.

Brand-Williams, W., Cuvelier, M. E. \& Berset, C. L. W. T. (1995). Use of a free radical method to evaluate antioxidant activity. LWT-Food Science and Technology, 28(1), 25-30.

Cerezo, A.B., Cuevas, E., Winterhalter, P., Garcia-Parrilla, M.C. \& Troncoso, A. M. (2010). Isolation, identification, and antioxidant activity of anthocyanin compounds in Camarosa strawberry. Food Chemistry, 123(3), 574-582.

Chandrasekara, N. \& Shahidi, F. (2012). Antioxidative potential of cashew phenolics in food and biological model systems as affected by roasting. Food Chemistry, 129, 1388-1396.

Cilla, A., González-Sarrías, A., Tomás-Barberán, F.A., Espín, J.C. \& Barberá, R. (2009). Availability of polyphenols in fruit beverages subjected to in vitro gastrointestinal digestion and their effects on proliferation, cell-cycle and apoptosis in human colon cancer Caco-2 cells. Food Chemistry, 114, 813-820.

Cilla, A., Perales, S., Lagarda, M.J., Barberá, R., Clemente, G. \& Farré, R. (2011). Influence of storage and in vitro 
gastrointestinal digestion on total antioxidant capacity of fruit beverages. Journal of Food Composition and Analysis, 24, 87-94.

During, A. \& Harrison, E. (2005). An in vitro model to study the intestinal absorption of carotenoids. Food Research International, 38, 1001-1008.

Escalada Pla, M. F., González, P., Sette, P., Portillo, F., Rojas, A. M., \& Gerschenson, L. N. (2012). Effect of processing on physico-chemical characteristics of dietary fibre concentrates obtained from peach (Prunus persica L.) peel and pulp. Food Research International, 49(1), 184192.

Fazzari, M., Fukumoto, L., Mazza, G., Livrea, M. A., Tesoriere, L. \& Marco, L. D. (2008). In vitro bioavailability of phenolic compounds from five cultivars of frozen sweet cherries (Prunus avium L.). Journal of Agricultural and Food Chemistry, 56(10), 3561-3568.

Guevara-Cruz, M., Lai, C. Q., Richardson, K., Parnell, L. D., Lee, Y. C., Tovar, A. R. \& Torres, N. (2013). Effect of a GFOD2 variant on responses in total and LDL cholesterol in Mexican subjects with hypercholesterolemia after soy protein and soluble fiber supplementation. Gene, 532, 211-215.

Gião, M. S., Gomes, S., Madureira, A. R., Faria, A., Pestana, D., Calhau, C. \& Malcata, F. X. (2012). Effect of in vitro digestion upon the antioxidant capacity of aqueous extracts of Agrimonia eupatoria, Rubus idaeus, Salvia sp. and Satureja Montana. Food Chemistry, 131, 761767.

Granado-Lorencio, F., Olmedilla-Alonso, B., Herrero-Barbudo, C., Blanco-Navarro, I., Pérez-Sacristán, B. \& BlázquezGarcía, S. (2008). Comparative in vitro bioaccessibility 
of carotenoids from relevant contributors to carotenoid intake. Food Chemistry, 102(3):641-648.

Green, R. J., Murphy, A. S., Schulz, B., Watkins, B. A. \& Ferruzzi, M.G. (2007). Common tea formulations modulate in vitro digestive recovery of green tea catechins. Molecular Nutrition \& Food Research, 51, 1152-1162.

Gorinstein, S., Bartnikowska, E., Kulasek, G., Zemser, M. \& Trakhtenberg, S. (1998). Dietary persimmon improves lipid metabolism in rats fed diets containing colesterol. The Journal of Nutrition, 128, 2023-2027.

Hernándiz, A. (1999). El cultivo de kaki en la comunidad valenciana. Cuadernos de tecnología agraria serie fruticultura No. 3. Generalitat Valenciana conselleria de agricultura, pesca y alimentación.

Kahle, K., Kempf, M., Schreier, P., Scheppach, W., Schrenk, D., Kautenburger, T. \& Richling, E. (2011). Intestinal transit and systemic metabolism of apple polyphenols. European Journal of Nutrition, 50, 507-522.

Landines, E., Martínez-Las Heras, R., Heredia, A. \& Andrés, A. (2014). Trabajo final de master: Extracción y caracterización de fibra de caqui. Universidad Politécnica de Valencia.

Martínez-Las Heras, R., Heredia, A., Castelló, M.L. \& Andrés, A. (2014). Influence of drying method and extraction variables on the antioxidant properties of persimmon leaves. Food Bioscience, 6, 1-8.

Martínez-Las Heras, R., Quifer-Rada, P., Andrés, A. \& Lamuela-Raventós, R. (2016). Polyphenolic profile of persimmon leaves by high-resolution mass spectrometry (LC-ESI-LTQ-Orbitrap-MS). Journal of Functional Foods, 23, 370-377. 
McDougall, G.J., Fyffe, S., Dobson, P. \& Stewart, D. (2007). Anthocyanins from red cabbage-stability to simulated gastrointestinal digestion. Phytochemistry, 68, 12851294.

Minekus, M., Alminger, M., Alvito, P., Ballance, S., Bohn, T., Bourlieu, C., ... Brodkorb, A. (2014). A standardised static in vitro digestion method suitable for food - An international consensus. Food \& Function, 5(6), 11131124.

Moure, A., Cruz, J.M., Franco, D., Domínguez, J.M., Sineiro, J., Domínguez, H., Parajó, J.C. (2001). Natural antioxidants from residual sources. Food Chemistry, 72, 145-171.

Ortega, N., Reguant, J., Romero, M.P., Macià, A. \& Motilva, M.J. (2009). Effect of fat content on the digestibility and bioaccessibility of cocoa polyphenol by an in vitro digestion model. Journal of Agricultural and Food Chemistry, 57, 5743-5749.

Ortega, N., Macià, A., Romero, M. P., Reguant, J., \& Motilva, M. J. (2011). Matrix composition effect on the digestibility of carob flour phenols by an in vitro digestion model. Food Chemistry, 124(1), 65-71.

Parada, J. \& Aguilera, J.M. (2007). Food microstructure affects the bioavailability of several nutrients. Journal of Food Science, 72, R21-R32.

Pérez-Vicente, A., Gil-Izquierdo, A. \& García-Viguera, C. (2002). In vitro gastrointestinal digestion study of pomegranate juice phenolic compounds, anthocyanins, and vitamin C. Journal of Agricultural and Food Chemistry, 50, 2308-2312.

Record, I.R. \& Lane, J.M. (2001). Simulated intestinal digestion of green and black teas. Food Chemistry, 73, 481-486. 
Rubió, L., Macià, A., Castell-Auví, A., Pinent, M., Blay, M. T., Ardévol, A. \& Motilva, M. J. (2014). Effect of the cooccurring olive oil and thyme extracts on the phenolic bioaccesibility and bioavailability assessed by in vitro digestion and cell models. Food Chemistry, 149, 277284.

Sakanaka, S., Tachibana, Y. \& Okada, Y. (2005). Preparation and antioxidant properties of extracts of Japanese persimmon leaf tea (kakinoha-cha). Food Chemistry, 89, 569-575.

Shahidi, F., Liyana-Pathirana, C.M. \& Wall, D.S. (2006). Antioxidant activity of white and black sesame seeds and their hull fractions. Food Chemistry, 99, 478-483.

Sorensen, M.D., Hsi, R.S., Chi, T., Shara, N., WactawskiWende, J., Kahn, A. J. \& Stoller, M. L. (2014). Dietary intake of fiber, fruit and vegetables decreases the risk of incident kidney stones in women: A women's health initiative report. The Journal of Urology, 192, 1694-1699.

Tavares, L., Figueira, I., Macedo, D., McDougall, G.J., Leitão, M.C., Vieira, H.L. \& Santos, C.N. (2012). Neuroprotective effect of blackberry (Rubus sp.) polyphenols is potentiated after simulated gastrointestinal digestion. Food Chemistry, 131, 14431452.

Thebaudin, J.Y., Lefebvre, A.C., Harrington, M. \& Bourgeois, C.M. (1997). Dietary fibres: Nutricional and technological interest. Trends in Food Science \& Technology, 8, 4148.

Van Soest, P. V., Robertson, J. B. \& Lewis, B. A. (1991). Methods for dietary fiber, neutral detergent fiber, and nonstarch polysaccharides in relation to animal nutrition. Journal of Dairy Science, 74(10), 3583-3597. 
Wootton-Beard, P.C., Moran, A. \& Ryan, L. (2011). Stability of the total antioxidant capacity and total polyphenol content of 23 commercially available vegetable juices before and after in vitro digestion measured by FRAP, DPPH, ABTS and Folin-Ciocalteu methods. Food Research International, 44, 217-224.

Zafrilla, P., Ferreres, F. \& Tomás-Barberán, F. A. (2001). Effect of processing and storage on the antioxidant ellagic acid derivatives and flavonoids of red raspberry (Rubus idaeus) jams. Journal of Agricultural and Food Chemistry, 49, 3651-3655.

Zhishen, J., Mengcheng, T. \& Jianming, W. (1999). The determination of flavonoid contents in mulberry and their scavenging effects on superoxide radicals. Food Chemistry, 64, 555-559. 